\title{
Análise da Região Produtiva Agrícola da soja na bacia hidrográfica do rio Paraná: um ensaio através de índices estatísticos em Climatologia
}

\author{
Beatriz Siqueira $^{(a)}$, Jonas Teixeira Nery ${ }^{(b)}$ \\ ${ }^{(a)}$ Doutoranda no Departamento de Geografia/Instituto de Geociências, Unicamp, biasiqueira@ige.unicamp.br \\ (b) Docente na Faculdade de Geografia, UNESP-Ourinhos, professor colaborador no curso de pós-graduação em \\ Geografia da UNICAMP. jonas@ ourinhos.unesp.br
}

Eixo: 3 - Climatologia em diferentes níveis escalares: mudanças e variabilidades

\section{Resumo}

\begin{abstract}
As atividades agrícolas vem sofrendo intensas transformações no Brasil, com a modernização no campo através do emprego de máquinas sofisticadas e com o surgimento da Agricultura de Precisão, atividades com tecnologia significativa que desempregaram milhares de trabalhadores rurais. Com as transformações no modo de produção vieram as transformações no espaço geográfico e assim, as Regiões Produtivas Agrícolas se constituíram no Brasil. A soja é uma das principais commodities brasileiras, cultivada em quase todo o país, especialmente na bacia do Paraná, área de estudo desta pesquisa, que engloba estados que são grandes produtores, como Mato Grosso, Paraná e Rio Grande do Sul. Com a finalidade de promover os estudos e avanços da Agricultura de Precisao no Brasil, bem como da Região Produtiva Agrícola da soja que se instaurou na bacia, o presente trabalho faz uso de dois índices estatísticos em Climatologia para quantificar a precipitação diária e mensal no território da bacia do Paraná e fazer a devida relação com a produção e rendimento de soja locais neste breve recorte.
\end{abstract}

Palavras chave: índices de chuva, variabilidade, agricultura, soja.

\section{Introdução e objetivos}

As transformaç̃oes ocorridas nas atividades agropecuárias no Brasil, nas últimas cinco décadas, têm profundos impactos sobre a (re) organização do território brasileiro, resultando em novos arranjos territoriais, estando entre eles a formação das Regiões Produtivas Agrícolas (ELIAS 2012).

Em seu trabalho intitulado Agronegócio e novas regionalizações no Brasil Elias (2012) explica serem as Regiões Produtivas Agrícolas, ou "RPAs", as grandes corporações concernentes às redes agroindustriais e os maiores agentes produtores do espaço agrário e urbano. Como consequência de tais processos, intensificam-se as relações campo-cidade e a urbanização, uma vez que as redes agroindustriais necessitam também de processos que se dão no espaço urbano próximo às áreas de produção agrícola e agroindustrial, incrementando o crescimento de cidades totalmente funcionais ao agronegócio, as quais passam a ter novas funções, como a de gestão desse agronegócio globalizado.

Dessa forma, é interessante pensar sobre a Agricultura de Precisão no Brasil, especialmente em um período onde a grande preocupação é a respeito da necessidade de se produzir alimentos para o abastecimento do mercado interno e excedentes para a exportação. Segundo Mantovani (2000) modificações drásticas no nível de aplicação tecnológica na agricultura neste final de século demandam do país atuação eficiente no sentido de incorporação a 
adaptação de inovações, principalmente em áreas estratégicas como a Biotecnologia e a própria Agricultura de Precisão.

A Agricultura de Precisão oferece novas e revolucionárias oportunidades de aplicação de inovações no campo da Automação, Instrumentação e Tecnologia da Informação, para o aprimoramento dos sistemas de informação agrícola. Através da análise detalhada dos campos de produção e do aprimoramento das técnicas de manejo, novos níveis de eficiência nos aspectos qualitativos e quantitativos da produção de culturas podem ser obtidos (MANTOVANI, 2000).

Sendo assim, o presente trabalho tem como finalidade analisar o cultivo da soja na bacia do Paraná, relacionando-o com a variabilidade da precipitação local através de dois índices estatísticos utilizados em Climatologia, de modo que seja possível constatar como o cultivar se comporta de acordo com a oferta hídrica na área de estudo, identificando em quais áreas da bacia o cultivo da soja é mais propício, levando em consideração as necessidades hídricas da planta e a concentração ou escassez de precipitação local.

\section{Fundamentação teórica}

As Regiões Produtivas Agrícolas (RPAs) são os novos arranjos territoriais produtivos totalmente associados ao agronegócio globalizado e, assim, inerentes às redes agroindustriais. Essas redes associam todas as atividades inerentes ao agronegócio, seja a agropecuária propriamente dita, sejam as atividades que antecedem essa produção e lhe são fundamentais, sejam as atividades de transformação industrial cuja matéria-prima provém da atividade agropecuária, seja de distribuição dos alimentos prontos, etc. (ELIAS, 2012).

Como o agronegócio globalizado se realiza totalmente a partir da dialética entre a ordem global e a ordem local, as RPAs estão conectadas aos centros de poder e consumo em nível mundial e, assim, as escalas locais e regionais articulam-se permanentemente com a internacional e o território organiza-se com base e imposições do mercado, comandado por grandes empresas nacionais e multinacionais. Isso significa que nas RPAs temos novos espaços de fluxos rápidos inerentes às redes agroindustriais, nas quais as verticalidades têm predominância sobre as horizontalidades (ELIAS, 2012, p. 155).

Diante dessa demanda da produção agropecuária globalizada, surge a Agricultura de Precisão, que consiste em um resgate do conhecimento detalhado, agora em grandes propriedades. De acordo com Mantovani (2000) o termo engloba o uso de tecnologias atuais para o manejo de solo, insumos e culturas, de modo adequado às variações espaciais e temporais em fatores que afetam a produtividade das mesmas.

A Agricultura de Precisão tem sido aplicada através do uso de tecnologias básicas, como o Sistema de Informações Geográficas (SIG), sensoriamento remoto em geral e o Sistema de Posicionamento Global, (GPS), no entanto, neste trabalho serão empregados no uso deste termo, índices estatísticos utilizados em análises climáticas, especialmente no que tange à distribuição e variabilidade da precipitação.

Os principais componentes do sistema da agricultura de precisão devem associar as medidas e compreensão da variabilidade. Posteriormente, o sistema deve usar a informação para manejar a variabilidade, associando a aplicação de insumos (fertilizantes, sementes, defensivos agrícolas, etc.) usando o conceito de manejo localizado 
e as máquinas e equipamentos para a correta aplicação dos diferentes insumos a serem manejados. Finalmente, e mais importante, esse sistema deve recordar a eficiência das práticas, com a finalidade de avaliar o seu valor para o agricultor (COELHO, 2005).

Ainda segundo Elias (2012), as RPAs apresentam muitas diferenças entre si, sobretudo porque cada commodity possui suas próprias exigências de insumos químicos, serviços, força de trabalho, tecnologia, capital, maquinário etc. o que resulta em arranjos territoriais produtivos distintos.

A soja é uma commodity que constitui uma das maiores cadeias agroindustriais do país. De acordo com Junior (2011) sua significância e envergadura ao agronegócio se dá pela sua dimensão produtiva (68,7 milhões de toneladas produzidas em 2009/010), territorial (23,5 milhões de hectares plantados em 2009/2010), econômica (5\% do PIB em 2008) e comercial (9,9\% do total de exportações de 2010).

As agroindústrias são o principal destino da soja no Brasil, segundo dados do Censo Agropecuário de 2006, mais de 17 milhões de toneladas do grão foram encaminhadas às unidades de esmagamento, o que representa 42,6\% do total comercializado no país. Em alguns estados, como Mato Grosso, Bahia, Goiás, Piauí e Minas Gerais, esse valor ultrapassa os $60 \%$, enquanto na região Sul são as cooperativas que controlam $77,5 \%$ da soja vendida pelos produtores, de acordo com dados de 2010 do Instituto Brasileiro de Geografia e Estatística (JUNIOR, 2011).

\subsection{A soja}

\section{- Origem}

De acordo com o Ministério da Agricultura, a soja é a cultura agrícola que mais cresceu nas últimas três décadas e corresponde a 49\% da área plantada em grãos do país. Cultivada especialmente nas regiões Centro-Oeste e Sul do país, a soja se firmou como um dos produtos mais destacados da agricultura nacional e na balança comercial.

A origem da cultura está na Ásia, mais precisamente na China antiga. Essa leguminosa constituía a base alimentar do povo chinês há mais de 500 anos (DE SOUSA CÂMARA, 2012).

No Brasil, a solja chegou na última década do século XIX, com curiosidade botânica, teve o seu cultivo implementado a partir dos anos 20 do século passado com os migrantes japoneses (PEIXINHO et al. 2003).

\section{- Necessidades hídricas}

Segunda a Empresa Brasileira de Pesquisa Agropecuária (EMBRAPA) a água constitui aproximadamente 90\% do peso da planta, atuando em praticamente todos os processos fisiológicos e bioquímicos. Desempenha a função de solvente, através da qual, gases, minerais e outros solutos entram nas células e movem-se pela planta. Tem, ainda papel importante na regulação térmica da planta, agindo tanto no resfriamento como na manutenção e distribuição do calor.

A disponibilidade da água é importante em dois períodos de desenvolvimento da planta: germinação e floração. No primeiro, tanto o excesso quanto o déficit hídrico são prejudiciais à obtenção de uma boa uniformidade na população de plantas. A semente de soja necessita absorver, no mínimo, 50\% de seu peso em água para assegurar boa germinação. Nessa fase, o conteúdo de água no solo não deve exceder a 85\% do total máximo de água disponível e nem ser inferior a 50\% (EMBRAPA, 2000). 
A necessidade de água da cultura da soja vai aumentando com o desenvolvimento da planta, atingindo o máximo durante o segundo período de desenvolvimento, a floração (7 a $8 \mathrm{~mm}$ por dia), decrescendo após esse período. Déficits hídricos expressivos, durante a floração e o enchimento de grãos provocam alterações fisiológicas na planta, como o fechamento estomáticos e o enrolamento de folhas, que consequentemente causam a queda prematura das folhas e flores e o abortamento de vagens, resultando, por fim, na redução do rendimento de grãos (EMBRAPA, 2000).

\subsection{A Bacia do Paraná}

A bacia do Paraná (Figura 1) é uma ampla região sedimentar do continente sul-americano que inclui porções territoriais do Brasil meridional, Paraguai oriental, nordeste da Argentina e norte do Uruguai, totalizando uma área que se aproxima dos 1,5 milhão de quilômetros quadrados (MILANI et al. 1994)

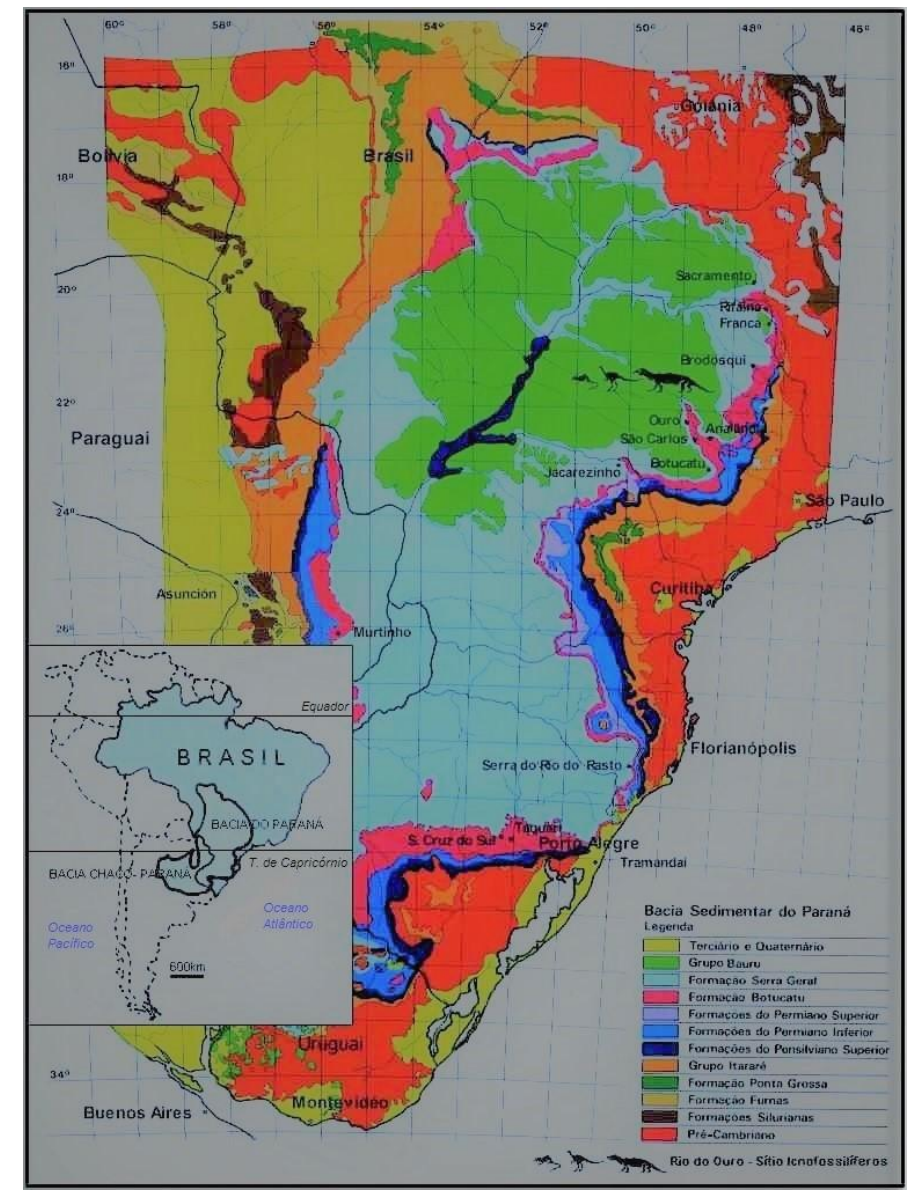

Figura 1- Localização da área de estudo.

Fonte: LEONARDI et al. (1999).

Adaptado por: SIQUEIRA, B. (2017).

A área de ocorrência da bacia que abrange o território brasileiro, objeto de estudo deste trabalho atinge cerca de $100.000 \mathrm{~km}^{2}$ e está compreendida entre os paralelos $16^{\circ}$ e $32^{\circ}$ de latitude $\mathrm{S}$ e os meridianos $47^{\circ}$ e $56^{\circ}$ de longitude W; a área restante encontra-se assim distribuída: Argentina $400.000 \mathrm{~km}^{2}$, Paraguai $100.000 \mathrm{~km}^{2} \mathrm{e}$ Uruguai $100.000 \mathrm{~km}^{2}$ (REBOUÇAS, 1976). 
As condições hidrológicas de uma região são determinadas, principalmente, por fatores de ordem climática e geológica. A geologia indica, na maioria dos casos, a importância e distribuição das estruturas armazenadoras de água subterrânea, enquanto que o clima dita a abundância e a variabilidade da sua realimentação no tempo e no espaço. A combinação destes fatores na área propicia, de maneira global, condições hidrológicas altamente favoráveis e privilegiadas (REBOUÇAS, 1976).

A soja, cultura a ser analisada na área de estudo manifesta-se em abundância especialmente no estado do Mato Grosso, como mostra a tabela abaixo (Tabela 1) designando as safras de 2015 e 2016, ambas nos meses de outubro, para o Brasil e demais estados compreendidos pela área de abrangência da bacia, em ordem decrescente de produtividade.

Tabela 1 - Produtividade de soja na Bacia do Paraná, em toneladas.

\begin{tabular}{ccc}
\hline $\begin{array}{c}\text { Safras de grãos de soja } \\
\text { (em toneladas) }\end{array}$ & $\begin{array}{c}\text { Safra 2015 } \\
\text { (out.) }\end{array}$ & $\begin{array}{c}\text { Safra 2016 } \\
\text { (out.) }\end{array}$ \\
\hline Brasil & $\mathbf{9 7 . 4 6 4 . 9 3 7}$ & $\mathbf{9 6 . 0 3 6 . 8 8 7}$ \\
Mato. Grosso & $\mathbf{2 7 . 8 5 0 . 9 5 4}$ & $\mathbf{2 6 . 2 7 7 . 7 5 3}$ \\
Paraná & $\mathbf{1 7 . 2 2 9 . 3 7 8}$ & $\mathbf{1 6 . 9 6 9 . 6 6 0}$ \\
Rio Grande do Sul & $\mathbf{1 5 . 7 0 0 . 2 6 4}$ & $\mathbf{1 6 . 1 8 9 . 8 3 4}$ \\
Goiás & $\mathbf{8 . 6 0 6 . 2 1 0}$ & $\mathbf{1 0 . 2 5 8 . 8 9 9}$ \\
Mato Grosso do Sul & $\mathbf{7 . 3 0 5 . 6 0 8}$ & $\mathbf{7 . 4 0 2 . 4 1 8}$ \\
Minas Gerais & $\mathbf{3 . 5 2 4 . 0 5 5}$ & $\mathbf{4 . 7 4 7 . 4 9 4}$ \\
São Paulo & $\mathbf{2 . 4 0 6 . 2 6 2}$ & $\mathbf{2 . 6 2 7 . 8 3 9}$ \\
Santa Catarina & $\mathbf{2 . 0 0 0 . 3 2 3}$ & $\mathbf{2 . 1 3 9 . 6 1 1}$ \\
Distrito Federal & $\mathbf{1 8 0 . 8 3 2}$ & $\mathbf{2 0 8 . 6 0 8}$
\end{tabular}

\section{Fonte: SIDRA/IBGE}

Organização: SIQUEIRA, B. (2016).

A Tabela 2 mostra o rendimento de grãos se soja no país, em quilogramas por hectare nos estados compreendidos pela bacia do Rio Paraná, em ordem decrescente de rendimento dos grãos. É possível observar que, embora os estados de Santa Catarina, São Paulo e Paraná liderem no rendimento dos grãos, todos os valores, nos diferentes estados se aproximam e ficam entre 2.000 e 3.000 quilogramas por hectare denotando a produtividade uma significância maior e mais precisa para a análise desta região produtiva agrícola através da variabilidade da precipitação.

\begin{tabular}{|c|c|c|}
\hline $\begin{array}{c}\text { Safras de grãos de soja } \\
\text { (em kg/ha) }\end{array}$ & $\begin{array}{l}\text { Safra 2015 } \\
\text { (out.) }\end{array}$ & $\begin{array}{l}\text { Safra 2016 } \\
\text { (out.) }\end{array}$ \\
\hline Brasil & 3.029 & 2904 \\
\hline Santa Catarina & 3.106 & 2.887 \\
\hline São Paulo & 3.039 & 3.172 \\
\hline Paraná & 3.288 & 3.117 \\
\hline Mato Grosso do Sul & 3.108 & 3.062 \\
\hline Mato Grosso & 3.106 & 2.887 \\
\hline Goiás & 2.640 & 3.125 \\
\hline Distrito Federal & 2.626 & 3.125 \\
\hline Minas Gerais & 2.654 & 3.254 \\
\hline Rio Grande do Sul & 2.983 & 2.972 \\
\hline
\end{tabular}

Fonte: SIDRA/IBGE 


\section{OS DESAFIOS DA GEOGRAFIA FÍSICA NA FRONTEIRA DO CONHECIMENTO Instituto de Geociências - Unicamp$$
\text { Campinas - SP }
$$ \\ 28 de Junho à 02 de Julho de 2017}

\section{Organização: SIQUEIRA, B. (2016).}

\section{Materiais e métodos}

Inicialmente realizou-se uma vasta coleta de dados diários de precipitação através de estações meteorológicas distribuídas ao longo do território que compreende a bacia do Paraná. Em seguida, esses dados foram tratados a fim de se adequarem aos softwares utilizados para os cálculos dos índices.

As isolinhas de precipitação foram elaboradas no software Golden Surfer 13, através do método de Krige de interpolação de dados, para a discussão e análise dos resultados obtidos.

As estações meteorológicas com dados diários de precipitação foram coletadas no site da ANA (Agência Nacional de Águas), no Portal SNIRH (Sistema Nacional de Informações sobre Recursos Humanos). A área da bacia do rio Paraná foi fragmentada, isto é, a coleta foi feita individualmente em cada estado compreendido pela área de estudo no território brasileiro. Ao todo conseguiu-se 67 estações pluviométricas distribuídas ao longo da área de estudo (Figura 2) e a escolha para cada uma delas obedeceu ao critério de melhor localização espacial.

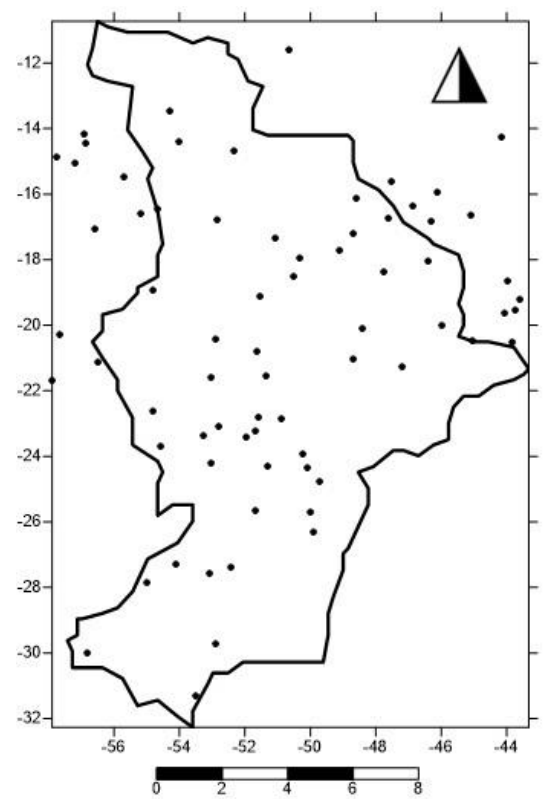

Figura 2 - Distribuição espacial das estações pluviométricas na área de estudo. Fonte: Agência Nacional de Águas (ANA). Organização: SIQUEIRA, B; NERY, J.T. (2017)

Devido a problemática da inconsistência de dados, extremamente significativa nos resultados finais do trabalho, buscou-se uma nova metodologia no que tange à disponibilidade de dados consistentes, que possibilitassem melhor qualidade à pesquisa. Dessa forma, passou-se a utilizar dados em ponto de grade, em formato NetCDF, um conjunto de dados disponível para a América do Sul, combinados de forma simples em campos diários de $1^{\circ}$ e $2,5^{\circ}$ (LIEBMANN et al. 2005)

Os campos de grade são feitos através de uma simples média de todas as estações disponíveis dentro de um raio específico de cada ponto de grade, para este trabalho, foram utilizadas as coordenadas geográficas (latitude e longitude) das estações meteorológicas obtidas através do site da ANA, foi através delas que se conseguiu os 
dados em ponto de grade. Esse conjunto de dados é público e o formato do arquivo é NetCDF, selecionado para compatibilidade entre plataformas e incorporação de coordenadas de grade e outros metadados úteis, disponível no site da Earth System Research Laboratory.

\section{- O Índice de Concentração - CI}

O Índice de Concentração (IC) elaborado por Javier Martin-Vide (2004), foi utilizado para determinar o impacto relativo que as diferentes classes de precipitação exercem na heterogeneidade da precipitação diária.

Baseado nas áreas $A^{\prime}$ e $S^{\prime}$ e comprimido pela curva, a linha de equidistribuição e $N^{\prime}{ }_{\mathrm{i}}(=100)$ é a diferença entre 5.000 e o valor de $A^{\prime}$. Os coeficientes $a$ e $b$ podem ser estimados por meio do método dos mínimos quadrados. Então, o índice de concentração, que se assemelha ao de Gini, pode ser definido como:

$$
C I=\frac{S^{\prime}}{5,000}=\frac{\left(5,000-A^{\prime}\right)}{5,000}
$$

De modo geral, segundo Javier Martin-Vide (2004), valores acima de 0,61 significam que 70\% da precipitação total está dentro de $25 \%$ dos dias mais chuvosos.

\section{- O Índice de Precipitação Concentrada - IPC}

Com a finalidade de quantificar a precipitação mensal e a heterogeneidade da precipitação em um ano Oliver (1980) e De Luis et al. (1997) desenvolveram o Índice de Precipitação Concentrada (IPC).

O índice modificado é expresso por:

$$
\mathrm{PCI}=100 * \frac{\sum_{i=1}^{12} p_{i}^{2}}{\left(\sum_{i=1}^{12} P_{i}\right)^{2}}
$$

Onde $p_{i}$ é a quantidade de chuvas do ith mês, calculado para cada um dos pluviômetros e para cada ano, durante o período de estudo. Conforme descrito por Oliver (1980), os valores de PCI (Precipitation Concentration Index) anuais abaixo de 10 indicam uma distribuição de precipitação mensal uniforme, enquanto os valores entre 11 e 20 denotam sazonalidade na distribuição das chuvas. Valores acima de 20 correspondem a clima com marcada variabilidade mensal na quantidade de chuva.

\section{Resultados e discussão}

Segundo dados do SIDRA (Sistema IBGE de Recuperação Automática) do mês de outubro de 2016, os estados que lideram em produção de toneladas de grãos de soja no Brasil são o Mato Grosso, o Paraná e o Rio Grande do Sul, respectivamente. Ambos os estados estão compreendidos no território da Bacia do Paraná, entretanto, os demais estados que também compõem sua área de abrangência também aparecem como produtores significativos da leguminosa, o que faz da Bacia do Paraná uma importante Região Produtiva Agrícola de grãos de soja no país. 
XVII Simpósio Brasileiro de Geografia Fisica Aplicada

I Congresso Nacional de Geografia Física

\section{OS DESAFIOS DA GEOGRAFIA FÍSICA NA FRONTEIRA DO CONHECIMENTO \\ Instituto de Geociências - Unicamp \\ Campinas - SP \\ 28 de Junho à 02 de Julho de 2017}

A figura a seguir (Figura 3) retrata a concentração da precipitação na área de estudo, entre 1970 e 2014, em quantificações diária e mensal, respectivamente.

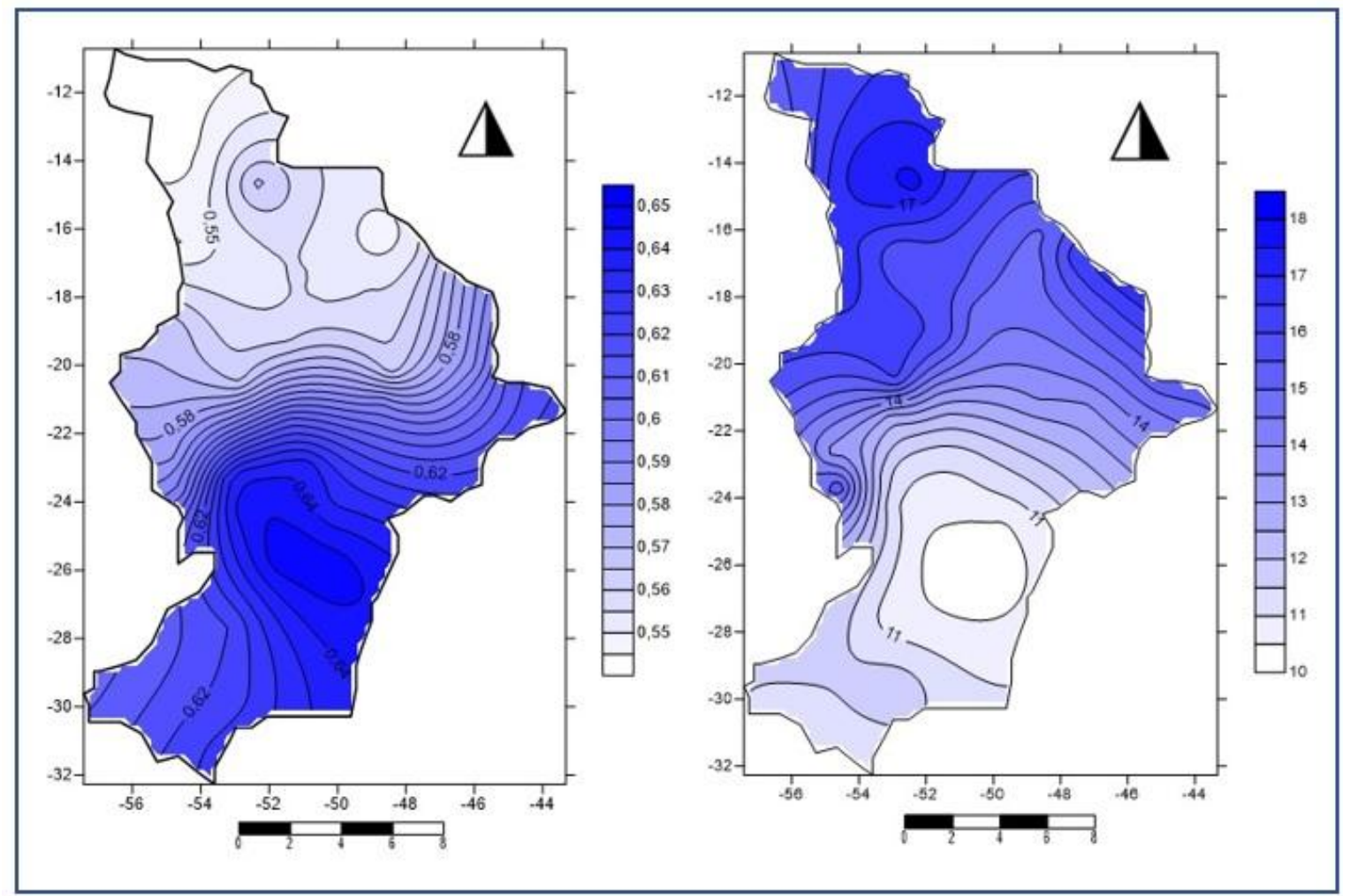

Figura 3 - Índice de Precipitação Concentrada na Bacia do Paraná, entre 1970 e 2014. Organização: SIQUEIRA, B. (2016).

A concentração diária da precipitação estimada através do Índice de Concentração está presente com maior significância no sul da Bacia do Paraná e Centro-Sul do Brasil. Os estados de São Paulo, Paraná, Santa Catarina e Rio Grande do Sul estão localizados sob essa região de elevada concentração diária da precipitação, acima de 0,61, o que significa que $70 \%$ do total diário de precipitação cai em $25 \%$ dos dias mais chuvosos (MARTINVIDE, 2004), o que explicaria a liderança no rendimento dos grãos e na produtividade.

Entretanto, de acordo com a Tabela 1 de produtividade, o estado do Mato Grosso lidera na produtividade, com produção superior a 26 milhões de toneladas, mas não está localizado na região de maior concentração diária da precipitação, o IC é igual ou menor que 0,55 . O estado apresenta elevada concentração mensal de precipitação (Figura 3), com valores do índice entre 14 e 18, denotando sazonalidade na distribuição das chuvas (OLIVER, 1980).

Dessa forma, constata-se que o estado do Mato Grosso não apresenta elevados percentuais diários de precipitação, como os estados do Paraná, Santa Catarina e Rio Grande do Sul, e que a maior contribuição da precipitação nessa localidade da bacia ocorre mensalmente e segue um padrão sazonal de distribuição. $\mathrm{O}$ fato de o estado ser o maior produtor de grãos de soja do Brasil pode ser explicado através dos avanços tecnológicos agrícolas, como a Agricultura de Precisão que possui, dentre tantas técnicas, a irrigação, que permitiria um bom monitoramento e desenvolvimento do cultivo no estado. 
A maior concentração de precipitação diária ao sul da bacia também pode ser explicada pela frequência e intensidade com as quais a precipitação ocorre, pois trata-se de uma região com eventos climáticos severos, como enchentes e inundações que ocasionam desabamento e deslizamento de terra. A maior concentração mensal da precipitação ao norte e extremo-Oeste da bacia, pode ser atribuída a menores frequência e intensidade da precipitação diária, mas a maiores percentuais de dias em que a precipitação de fato ocorreu, que nas localidades do Sul e extremo-Sul da bacia.

\section{Considerações finais}

Os índices de Concentração e de Precipitação Concentrada se mostraram ferramentas eficientes na quantificação da precipitação na Bacia do Paraná e revelaram-se como instrumentos interessantes que podem ser adicionados a tantos outros constituintes da Agricultura de Precisão. Além do mais, apresentaram informações importantes sobre a distribuição, frequência e intensidades da mesma.

A disponibilidade da água no cultivo da soja é importante em dois períodos de desenvolvimento da planta: germinação e floração. No primeiro o conteúdo de água no solo não deve exceder a $85 \%$ do total máximo de água disponível e nem ser inferior a 50\% (EMBRAPA, 2000), o que explica a grande produtividade e rendimento do cultivo na Bacia do Paraná, região que, de acordo com os Índices, se apresentou com chuvas bem distribuídas em toda a área de abrangência, IC entre 0,55 e 0,62 e IPC entre 14 e 19.

Por tratar-se de uma região que não apresenta relevância em déficits hídricos expressivos, o cultivar não deve sofrer alterações fisiológicas, como fechamento estomáticos e enrolamento das folhas, situações que causam a queda prematura das folhas e flores e o abortamento de vagens, que trariam como consequência a redução do rendimento de grãos (EMBRAPA, 2000).

Dessa forma, a precipitação com as devidas proporções encontradas na Bacia do Paraná, consiste em um elemento positivo ao desenvolvimento, produção e rendimento da leguminosa no local. O estado do Mato Grosso, líder na produção dos grãos de soja na região da bacia é o que apresenta as menores concentrações diárias de chuva, fato que prejudicaria o desenvolvimento da planta nos períodos de germinação e floração.

\section{Referências bibliográficas}

ANA. Agência Nacional de Águas. Disponível em: www.ana.gov.br. Acesso em: abr. 2016.

BINACIONAL, ITAIPU. Disponível em: $<$ https://www.itaipu.gov.br/energia/bacia-do-rio-parana $>$. Acesso em 14 de junho de 2016 v. 28, 2010.

BROOKS, C. Ernest Pelham et al. Handbook of statistical methods in meteorology. Handbook of statistical methods in meteorology. 1953.

COELHO, Antônio Marcos. Agricultura de Precisão: manejo da variabilidade espacial e temporal dos solos e culturas. Agricultura, v. 1518, n. 4277, p. 46, 2005.

DE LUIS, M. et al. Distribución espacial de la concentración y agresividad de la lluvia en el territorio de la Comunidad Valenciana. Cuaternario y Geomorfología, v. 11, n. 3-4, p. 33-44, 1997.

DE SOUSA CÂMARA, Gil Miguel. INTRODUÇÃO AO AGRONEGÓCIO SOJA1. 
ELIAS, Denise. Agronegócio e novas regionalizações no Brasil. Revista Brasileira de Estudos Urbanos e Regionais, v. 13, n. 2, p. 153-167, 2012.

EMBRAPA. Empresa Brasileira de Pesquisa Agropecuária. Disponível em: https://www.embrapa.br/soja. Acesso em: nov. de 2016.

ESRL. Earth System Research Laboratory. Disponível em: http://www.esrl.noaa.gov/psd/people/brant.liebmann/south_america_precip.html. Acesso em: out. de 2016.

Golden Software. Disponível em: http://www.goldensoftware.com/products/surfer. Acesso em set. 2016.

JUNIOR, Valdemar João Wesz. Dinâmicas e estratégias das agroindústrias de soja no Brasil. Editora Epapers, 2011.

LEONARDI, Giuseppe; CARVALHO, I. S. Jazigo Icnofossilífero do Ouro-Araraquara (SP). Schobbenhaus, C.; Campos, DA; Queiroz, ET; Winge, M, 1999.LUIS, M. de et al. Precipitation concentration changes in Spain 1946-m]

LIEBMANN, Brant; ALLURED, Dave. Daily precipitation grids for South America. Bulletin of the American Meteorological Society, v. 86, n. 11, p. 1567, 2005. 2005.Natural Hazards and Earth System Science, v. 11, n. 5, p. 1259-1265, 2011.

MANTOVANI, Evandro Chartuni. Agricultura de precisão e sua organização no Brasil. Agricultura de precisão. Viçosa: UFV, p. 77-92, 2000.

MARTIN-VIDE, J. Spatial distribution of a daily precipitation concentration index in peninsular Spain. International Journal of Climatology, v. 24, n. 8, p. 959-971, 2004.

MILANI, Edison José; FRANÇA, Almerio Barros; SCHNEIDER, R. L. Bacia do Paraná. Boletim de Geociências da PETROBRÁS, v. 8, n. 1, p. 69-82, 1994.

OLIVER, J. E. Monthly precipitation distribution: a comparative index. The Professional Geographer, v. 32, n. 3, p. 300-309, 1980.

PEIXINHO, Dimas Moraes et al. A reestruturação espacial e a interação entre local e o global: o exemplo da soja. Boletim Goiano de Geografia, v. 23, n. 1, p. 83-112, 2003.

REBOUCCAS, A. C. Recursos hídricos subterrâneos da Bacia do Paraná [Underground water resources of the Paraná basin]. 1976. Tese de Doutorado. PhD Thesis, University of São Paulo, Brazil.

SHAW, G., WHEELER, D. Statistical techniques in geographical analysis. Halsted Press, New York, 1994. 